\title{
VULNERABILIDADE SOCIAL, JUVENTUDE E AS POLÍTICAS DE EDUCAÇÃO PÚBLICA
}

\author{
Edilair Alcantara Barreto Gomes ${ }^{1}$ \\ Nildete Costa da Mata²
}

\section{Resumo}

Este trabalho tem como finalidade contribuir com o processo de discussão sobre a política de educação pública, enquanto demanda da juventude em vulnerabilidade social, retratando significativos e desafiadores avanços, incertezas e implicações, principalmente no que se refere a política pública. $\mathrm{O}$ artigo apresenta conceitos, mobilizações, possibilidade de reflexões, transformações, autores que trabalham nessa área, a crise de referências e seus efeitos na subjetividade dos jovens na contemporaneidade, gerando angústias, bem como o resgate de dados históricos explanados nas leis e documentos oficiais, citando à atual situação do setor educacional e mostrando de uma maneira valorativa a importância do trabalho no espaço escolar, responsável e apropriado para concretizar os processos de desenvolvimento educativo e afetivo da criança e adolescente no âmbito educacional.

Palavras-chave: Vulnerabilidade social. Juventude. Educação. Política pública.

\begin{abstract}
:
This work aims to contribute to the process of discussion on public education policy, as a demand of youth in social vulnerability, portraying significant and challenging advances, uncertainties and implications, especially with regard to public policy. The article presents concepts, mobilizations, the possibility of reflections, transformations, authors working in this area, the crisis of references and their effects on the subjectivity of young people today, generating anguish, as well as the rescue of historical data explained in laws and official documents, citing the current situation in the educational sector and showing in an appreciative way the importance of work in the school environment, responsible and appropriate to concretize the processes of educational and affective development of children and adolescents in the educational field.
\end{abstract}

Keywords: Social vulnerability. Youth. Education. Public policy.

\section{INTRODUÇÃO}

A vulnerabilidade vem crescendo entre os jovens brasileiros, apresentando muitos desafios. Verifica-se que muitos são os fatores que agravam a situação da juventude, principalmente os que vivem em situação de

\footnotetext{
${ }^{1}$ Mestra em Ciências da Educação pela Facultad Interamericana de Ciencias Sociales (FICS), Licenciada em Ciências Sociais pela Universidade Federal da Bahia (UFBA), professora no Colégio Estadual Prof. ${ }^{a}$ Maria Anita (CEPMA), Salvador - BA/Brasil. E-mail: edilair21@gmail.com.

2 Mestra em Ciências da Educação pela Facultad Interamericana de Ciencias Sociales (FICS), Especialista em Alfabetização pela Olga Metting, Licenciada em Letras vernáculas pela Universidade Católica de Salvador - (UCSAL), Professora do Colégio Estadual Alípio Franca ( CEAF), Salvador- BA/Brasil. E-mail: nildetemata@gmail.com.
} 
pobreza extrema, de desemprego e com dificuldades de acesso a uma educação de qualidade.

Diante de tal constatação, este artigo vem contribuir com o debate sobre vulnerabilidades sociais, a partir de estudiosos, entretanto, vamos nos ater a algumas referências, como as de autores da Comissão Econômica para a América Latina e o Caribe (CEPAL) que organizaram, em junho de 2001, um seminário preparatório para documentos, recorrendo ao conceito para debate sobre a situação da América Latina.

Parte-se, então, do conceito corrente de debilidades, ou fragilidades, para elaborações que fogem do sentido passivo que sugere tal uso. $\mathrm{Na}$ elaboração mais conceitual, vulnerabilidade pede recorrência a diversas variáveis de análise - indivíduos, domicílios e comunidades -, além de recomendar que se identifiquem cenários e contextos (VIGNOLI; ARRIAGADA; FILGUEIRA, 2001). Pede, portanto, diferentemente do conceito de exclusão, olhares para múltiplos planos, e, em particular, para estruturas sociais vulnerabilizantes ou condicionamentos de vulnerabilidades, bem como 0 repensar as políticas de educação pública para a juventude.

Desse modo, este texto objetiva analisar a realidade descrita acima, qual seja, a questão da juventude em vulnerabilidade frente as possibilidades e implicações do processo de implantação e implementação de política pública de educação.

\section{DESENVOLVIMENTO}

A partir de autores como Vignoli (2001, p. 2) compreende-se que a vulnerabilidade como a falta de acesso às estruturas de oportunidade oferecidas pelo mercado, estado ou sociedade, apontando a carência de um conjunto de atributos necessários para o aproveitamento efetivo da estrutura de oportunidades existentes. Busso (2001, p. 20-21) considera a vulnerabilidade como a debilidade dos ativos que indivíduos, famílias ou grupos dispõem para enfrentar riscos existentes que implicam a perda de bem estar.

De maneira semelhante, Katzman (1999, p. 171-173) nos apresenta um conjunto de ativos que considera necessários para o aproveitamento efetivo da estrutura de oportunidades existentes e como a debilidade destes pode impedir 
ou deteriorar situações de bem estar. Caroline Moser (1998, p. 1-19) apreende este tema pela relação entre disponibilidade dos recursos materiais e simbólicos dos atores e o acesso à estrutura de oportunidades do meio em que vive cujo descompasso torna-se empecilho à ascensão social desses mesmos atores.

Compreende-se, portanto, a vulnerabilidade como uma conjunção de fatores, sobrepostos de diversas maneiras e em várias dimensões, de modo a tornar o indivíduo ou grupo mais suscetível aos riscos e contingências (BRUSEKE, 2006, p. 69-80). Cabe considerar, todavia, que seu caráter multifacetado é não apenas uma vantagem, mas também o grande empecilho para sua análise, na medida em que dificulta a definição de variáveis precisas e a construção de um indicador exato.

Não poderemos esquecer que, muitos autores, como os citados, recorrem, por exemplo, ao conceito de vulnerabilidades sociais para tentar desconstruir sentidos únicos e identificar potencialidades de acionar indivíduos para resistir e enfrentar situações socialmente negativas. Haveria, portanto, uma vulnerabilidade positiva, quando se aprende, pelo vivido, a tecer formas de resistências, formas de lidar com os riscos e obstáculos de modo criativo.

O conceito constituinte desse plano de vulnerabilidade (a vulnerabilidade positiva) seria subsidiário dos debates de Bourdieu (2001) sobre capital cultural, social e simbólico, ou seja, o que se adquire por "relações de comunicação", tomando consciência de violências simbólicas, do que aparece como arbitrário. É quando as vulnerabilidades vividas trazem a semente positiva de "um poder simbólico de subversão" (Ibid., p.15).

Ainda considerando os estudos sobre vulnerabilidades sociais que acessam os indivíduos, as famílias e grupos na comunidade por meio de instâncias de consagração intelectual e artística, por exemplo, as escolas, as academias, os salões, as associações científicas e culturais, e, também, as instâncias de difusão cultural, tais como as editoras, a imprensa, os museus etc., tende-se a trabalhar com o esperado em diferentes sistemas de linguagens, reconhecendo a força da subjetividade, do desejo, e a distância entre o vivido e o esperado quanto a direitos humanos. Contudo, é necessário, pesquisar mais sobre ambientes ou 'inseguranças e incertezas'(Vignoli, 2001; Cepal, 2000), bem como sobre o reconhecimento do direito a ter direitos, tal 
como o refere Hanna Arendt no debate sobre cidadania (apud Duarte 2001).

Para tanto, cabem recorrer a diversas formas de análises, tais como: a pesquisa sobre vulnerabilidades contemporâneas na América Latina, como a 'juvenilização' da mortalidade, em particular entre grupos na pobreza e por causas violentas, as quais sinalizariam que não basta referir-se a direitos individuais, mas também de grupos e gerações e a características de um tempo e de sociedades. Desse modo, quais seriam as marcas desta geração, e de gerações nessas sociedades?

É possível, identificar aspectos que afetam a juventude, por exemplo, o desencanto, as incertezas em relação ao futuro, o distanciamento em relação às instituições, a descrença na sua legitimidade e na política formal, além de resistência a autoritarismos e 'adultocracia'. Nesse caso, a escola e a família já não teria a mesma referência:

\begin{abstract}
Que tiveram para outras gerações, além de que há diversidades quanto a construções dessas referências em grupos em uma mesma geração. Por outro lado, o apelo da sociedade de espetáculo e o apelo aos padrões de consumo conviveriam com chamadas para a responsabilidade social e o associativismo. Essas e outras tendências contraditórias também potencializariam vulnerabilidades negativas e positivas (no sentido de fragilidades, obstáculos, capital social e cultural e formas de resistência no plano ético cultural). (CASTRO; ABRAMOVAY, 2002, p.28).
\end{abstract}

Dessa forma, discutir sobre juventude nos mobiliza a refletir a respeito de modernidade e sua realização em distintos planos e para distintos grupos sociais. Alguns autores de textos que subsidiaram a Reunião de Cúpula da CEPAL, que foi realizada em Salvador, Bahia, em 2002, e cujo tema foi às vulnerabilidades sociais, ao se referirem ao enfoque de vulnerabilidade, consideram os 'choques para as comunidades, lares e indivíduos', o 'enfoque dos riscos' e o 'enfoque dos ativos', ou a intenção de identificar 'recursos mobilizáveis nas estratégias das comunidades, lares e pessoas' (VIGNOLI, 2001, p. 58).

Caberia, por outro lado, ter o cuidado de não incorrer em uma falácia de níveis equivocados, devendo o pesquisador estar consciente de que pode haver contradição de sentidos também entre subunidades, ou componentes de uma determinada unidade, por exemplo, entre pais e filhos, ou membros da família homens e outros membros, mulheres. Não basta, portanto, referir-se a famílias vulneráveis (ARRIAGADA, 2001, p. 67). 
Enfim, autores que recorrem ao conceito de vulnerabilidades sociais (VIGNOLI; FILGUEIRA; ARRIAGADA, 2001) indicam a dialética possível no uso do conceito, referindo-se tanto ao negativo, ou seja, a obstáculos para as comunidades, famílias e indivíduos, assim como a riscos, quanto ao positivo, considerando possibilidades, ou a importância de se identificarem "recursos mobilizáveis nas estratégias das comunidades, famílias e indivíduos" (VIGNOLI, 2001, p. 58).

Assim, o universo da juventude não fica desassociado do cenário cultural, político e econômico do qual se encontra, mas implica diretamente em modelos que favorecem um estilo de comportamento e um modo de agir característicos. Ao observar os valores atualmente imputados pela publicidade à juventude, percebe-se que esses valores coincidem com muitas das qualidades atribuídas ao moderno: grande interesse pela novidade, extravagância, irreverência, espontaneidade, ousadia, rebeldia, exclusividade, diferença, entre outros.

As grandes transformações produzidas torna-se algo de fundamental relevância nesse período, tanto na área comportamental quanto no modelo e no sentido existencial, desvinculando valores outrora definidos como absolutos dentro de uma dinâmica social. Assim, a modernidade proporcionou algumas mudanças, entre elas a burocratização dos domínios da atividade humana e o desencantamento do mundo.

Esse desencantamento do mundo, segundo Max Weber (1981, p. 22) impacta as novas formas de relacionamento e as esferas políticas e sociais. Esse período pós-industrial inicia uma fase que se torna necessária perante os novos modelos econômicos, políticos e sociais. Não se enfatiza mais, como anteriormente, somente as questões religiosas e supersticiosas, mas também é levada em consideração a capacidade produtiva do ser humano.

Essas prerrogativas são de elevada importância para relacioná-las com o contexto de mudanças, e a partir desses dados confrontá-las com as tendências modernas da juventude.

A Declaração Universal dos Direitos Humanos, pedra fundamental de convivência civilizada, estabelece, no seu art. $3^{\circ}$, que "todo indivíduo tem direito à vida, à liberdade e à segurança pessoal" e adiciona, no art. $5^{\circ}$ : "ninguém será submetido à tortura nem a penas ou tratamentos cruéis, 
desumanos ou degradantes". Mais recente, a Declaração Universal dos Direitos da Criança estabelece, no seu Princípio VI - Direito ao amor e à compreensão por parte dos pais e da sociedade, que "a criança necessita de amor e compreensão, para o desenvolvimento pleno e harmonioso de sua personalidade".

A Constituição Federal estipula, no seu art. 227, estabelece que: "É dever da família, da sociedade e do Estado assegurar à criança, ao adolescente e ao jovem, com absoluta prioridade, o direito à vida, à saúde, à alimentação, à educação, ao lazer, à profissionalização, à cultura, à dignidade, ao respeito, à liberdade e à convivência familiar e comunitária, além de colocálos a salvo de toda forma de negligência, discriminação, exploração, violência, crueldade e opressão".

No Estatuto da Criança e do Adolescente, promulgado em 1990, considerado por muitos como um dos mais avançados do mundo, também contempla, no seu art. $4^{\circ}$ : "É dever da família, da comunidade, da sociedade em geral e do poder público assegurar, com absoluta prioridade, a efetivação dos direitos referentes à vida, à saúde, à alimentação, à educação, ao esporte, ao lazer, à profissionalização, à cultura, à dignidade, ao respeito, à liberdade e à convivência familiar e comunitária".

Ainda, assim, todo esse cabedal de recomendações, normas e resoluções, cotidianamente nos surpreende com notícias de graves violações, de atos de extrema barbárie praticados, em muitos casos, pelas pessoas ou instituições que deveriam ter a missão de zelar pela vida e pela integridade dessas crianças e adolescentes: suas famílias e as instituições públicas ou privadas que, em tese, seriam os responsáveis pelo resguardo dos mesmos.

Nos dias atuais, a infância e juventude retratam um cenário de crise. A crise de referências e seus efeitos na subjetividade contemporânea, consequentemente, gerando uma angústia e a possibilidade de reflexões. Gerações anteriores foram educadas com a expectativa de que o mundo teria um sentido e um futuro.

A sociedade está sendo confrontada com a experiência do naufrágio do modelo de esperança na modernidade, mergulhando em um sentimento angustiante, até dramático, de desemparo, resultante do desaparecimento de limites, os excessos do consumismo, incapacidade de aceitar uma decepção 
ou uma situação negativa, a busca pelo prazer a qualquer preço, onde a satisfação se tornou uma norma social.

Vale destacar, a ideologia capitalista, como marco do individualismo e da competitividade, desaparecendo ou distanciando da solidariedade, da colaboração entre as pessoas, resultando em um sentimento de vazio. Percebe-se que o perfil de nossa sociedade é assustador, com crise de autoridade paterna, depressão endêmica, suicídios, consumo de drogas, famílias desestruturadas e vulnerabilidade de crianças e adolescentes.

Por outro ângulo, as situações de vulnerabilidade infanto-juvenil e famílias passivas e dependentes tem gerado um elevado comprometimento da autoestima, atributos negativos pessoais diante das condições histórico-sociais. Observa-se que "a convivência familiar, nesta era nuclear, reduziu-se consideravelmente e, mesmo no tempo livre, a família encontra-se passiva e silenciosamente assistindo televisão, 'reunida e não unida" (MILIANI, 1991, p.390).

Assim, a família, como representante privilegiado de transmissão de valores, transformou-se em uma instituição sem força e eficácia reduzidas. Não existe tempo para o diálogo familiar. Por sua vez, a escola como instituição que pode influenciar o desenvolvimento de crianças e adolescentes em um significativo tempo de suas vidas, responsável na mediação entre eles e a sociedade. É papel da escola não apenas transmitir informações, como também formar cidadãos. Em outras palavras, além de avaliar se:

Os alunos estão aprendendo ou não, é função da escola compreender qual é o conhecimento que está sendo adquirido, qual a aplicabilidade desse conhecimento, quais os subsídios que o ensino oferece ao indivíduo para enfrentar melhor a vida e quais as contribuições na formação da sua autoimagem. A escola deve promover um ambiente e práticas que facilitem a aprendizagem, a criatividade, a expressão dos potenciais, a socialização, através de uma conduta ética de respeito e apoio recíprocos (DABAS, 2005, p. 17).

Para além dessas pontuações, os limites estão cada vez mais ausentes na vida dos jovens. Apesar de se compreender a importância do exercício da autoridade, alguns estudos têm evidenciado crianças e adolescentes apresentando dificuldades na construção de vínculos efetivos: 
educativos (família e escola). Por ser uma instituição responsável pelos processos de desenvolvimento educativo e afetivo da criança e do adolescente, a escola também dispõe de uma autoridade em continuação à autoridade da família: autoridade que deve ser legítima, com suas normas, regulamentos e proibições (LÉVY, 2001, p.39).

O espaço escolar por ser responsável pelos processos de desenvolvimento educativo e afetivo da criança e adolescente, esta dispõe de autoridade em continuação à família, assegurada por normas, regulamentos, limites. Contudo, sabemos que a relação educador-educando, também se encontra fragilizada na construção de regras e limites, resultando assim, em muitos jovens, um sentimento crescente de insegurança e não de pertença com a instituição (PEREIRA, 2009, p. 57).

Nesse contexto, há muito a ser feito e de se considerar no que concerne aos índices de vulnerabilidade infanto-juvenil. Consultando dados de pesquisa da UNESCO, identificam-se informações expressivas quanto ao índice de vulnerabilidade de jovens no Brasil, destacando à elevação da violência.

Observa-se que nos dados de pesquisa da UNESCO em 2017, o Índice de Vulnerabilidade Juvenil à Violência, 2017 - (IVJ/2017) é um indicador, desenvolvido pela Secretaria Nacional de Juventude (SNJ) em parceria com o Fórum Brasileiro de Segurança Pública, os quais agregam dados relativos às dimensões consideradas chave na determinação da vulnerabilidade dos jovens à violência, tais como taxa de frequência à escola, escolaridade, inserção no mercado de trabalho, taxa de mortalidade por homicídios e por acidentes de trânsito. Este nos fornece um campo norteador das políticas públicas de juventude, parcela da população mais afetada pela violência no Brasil.

Pode-se, também, considerar um indicador inovador, para além das variáveis que compõem o IVJ de 2014, ano base 2012, o novo índice abrange a população brasileira de 15 a 29 anos, idade estabelecida no Brasil como população jovem após a aprovação do Estatuto da Juventude (Lei $n^{\circ}$. 12.852/2013), em 2013 (UNESCO, SP.: SNJ, 2017. 92 p. ilus).

Esse estudo constata, ainda, que em todas as unidades da federação (UF), com exceção do Paraná, as jovens negras são mais vulneráveis à violência do que as brancas. Os dados são de 2015, mas com o lançamento do relatório em 11/12/2017, no Auditório da Secretaria Nacional de Juventude com 
a apresentação dos dados, destacou-se o aspecto inovador como índice que traz pela primeira vez o recorte de vulnerabilidade à violência sobre a juventude brasileira na faixa de 15 a 29 anos, que foi a idade definida para jovem, em 2013, pelo Estatuto da Juventude (Lei 12.852/2013). Até a edição de 2014 (dados de 2012), o IVJ era calculado para a faixa etária dos 12 aos 29 anos, com a:

Nova faixa etária, essa edição manteve os dois índices da edição de 2014 - o IVJ-Violência nos Municípios e o IVJ-Violência e Desigualdade Racial das unidades da federação (UFs) - e incluiu uma análise adicional sobre desigualdade entre jovens mulheres brancas e negras. O IVJ Violência nos Municípios comporta indicadores de mortalidade por homicídios, de mortalidade por acidentes de trânsito, de frequência à escola e situação de emprego, de pobreza e de desigualdade. Já o IVJ Violência e Desigualdade Racial, analisa a situação de vulnerabilidade para as 27 unidades da federação com base nos mesmos indicadores utilizados no município e acrescenta o componente de desigualdade racial (risco de um jovem negro ser morto em relação ao mesmo risco para um jovem branco) (UNESCO, SP: SNJ, 2017. p 93).

De forma extraordinária, nessa edição, acima mencionada, foram incluídos dados e análises referentes ao risco de uma jovem negra ser vítima de homicídio em comparação com uma jovem branca. O estudo é resultado de uma parceria entre a Secretaria Nacional de Juventude (SNJ) da Presidência da República e da Representação no Brasil da Organização das Nações Unidas para a Educação, a Ciência e a Cultura (UNESCO no Brasil), com apoio técnico do Fórum Brasileiro de Segurança Pública:

As estatísticas apresentadas pelo Índice de Vulnerabilidade Juvenil à Violência 2017 serão utilizadas para embasar o Novo Plano Juventude Viva, da Secretaria Nacional de Juventude, com ações de inclusão social e autonomia para os jovens de 15 a 29 anos expostos às situações de violência nos municípios de maior vulnerabilidade para a juventude, com foco prioritário na população negra. Os dados também irão subsidiar o governo brasileiro na elaboração e na implementação de políticas sociais nos segmentos vulneráveis (UNESCO, BRASIL, 2017. p. 93).

O relatório foi lançado por ocasião do Dia dos Direitos Humanos, celebrado no dia 10 de dezembro de 2017, e no âmbito da campanha Vidas Negras, pelo fim da violência contra jovens negros. Foi anunciada pelas Nações Unidas no Brasil, em 7 de novembro de 2017 e ligada à Década Internacional de Afrodescendentes (2015 - 2024). Essa campanha quer sensibilizar sobre o peso do racismo no quadro de violência e letalidade no 
país. No Brasil, 23 mil jovens negros são mortos por ano (BRASIL, UNESCO, Mapa da Violência, 2016, p. 8). O IVJ 2017 mostra que:

No topo da desigualdade racial e de gênero entre as taxas de homicídio estão os estados do Rio Grande do Norte, onde as jovens negras têm 8,11 mais chances de serem assassinadas em relação às jovens brancas, seguido do Amazonas $(6,97)$ e da Paraíba $(5,65)$. No Maranhão (1.10) e em Tocantins (1.15) as diferenças de risco de uma jovem negra e de uma jovem branca sofrer homicídio são as menores registradas no estudo. O Paraná é o único estado da Federação onde mulheres jovens brancas correm mais risco de serem assassinadas do que as jovens negras. (UNESCO, BRASIL, 2017. p. 8).

Considerando que os jovens em 24 unidades da federação, encontramse a chance de um jovem negro, seja do sexo masculino ou feminino:

Morrer assassinado é 2,7 vezes maior do que a de um jovem branco. Quanto às outras três UFs brasileiras, o Paraná tem uma taxa de mortalidade de jovens brancos superior àquela registrada entre os jovens negros; em Tocantins o risco é bastante próximo, e em Roraima não foi possível realizar o cálculo de risco uma vez que o estado não registrou morte de nenhum jovem branco no período. (UNESCO, BRASIL, IVJ à violência, 2017. p. 92).

Algumas pesquisas focais sugerem que, além da falta de oportunidades de alternativas de lazer, de trabalho é uma marca singular dos jovens, nestes tempos, é a sua vulnerabilidade à violência, o que se traduz na morte precoce de tantos. De fato, alguns dos autores citados e outros consideram que, se a falta de alternativas de trabalho e lazer não é traço novo na vida dos jovens de baixa renda no Brasil, o medo, a exposição à violência e a participação ativa em atos violentos e no tráfico de drogas seriam marcas identitárias de uma geração, de um tempo, no qual vidas jovens são eliminadas.

Atualmente, essa eliminação ocorreria mais que em nenhum outro período da idade moderna, exceto em circunstâncias de guerra civil ou entre países. Ou seja: a violência que mata e sangra seria marca dos tempos atuais e não peculiar de uma classe, a pobre, fato que se destaca em pesquisa sobre juventude e violência em Brasília, entre jovens de classe média e alta, que também adverte para a propriedade de se considerar a juventude no plural: "Não há um tipo único de jovem. Os jovens da periferia apresentam descontentamento por sua exclusão social agravada, circunstancialmente de forma violenta, buscam reconhecimento e valorização como cidadãos" (CASTRO; ABRAMOVAY, 2002, p.30). 
Nesse estudo progressivo e sistemático, reporta-se para dados, que mais uma vez comprovam o preocupante quadro de mortes de jovens negros que poderiam ser evitados. Entende-se a importância do lançamento da atualização do Índice de Vulnerabilidade Juvenil à Violência, que na edição de 2017 traz, também, uma clara indicação das questões de gênero. Dentre as várias conclusões desse estudo, merece destaque a análise do representante a.i. da UNESCO no Brasil, Marlova Jovchelovitch Nolet, afirmando que:

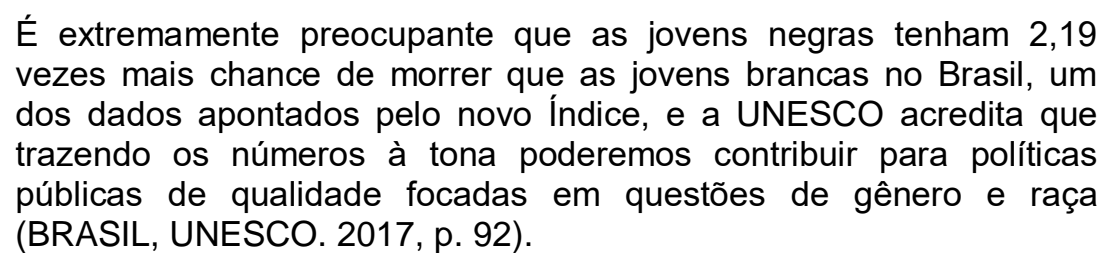

Outra informação relevante, mais uma vez revelada pelo relatório Índice de Vulnerabilidade Juvenil à Violência, 2017 é que o IVJ - Violência e Desigualdade Racial é medido para as UFs e pode variar de 0 (nenhuma vulnerabilidade) até 1 (máxima vulnerabilidade).

Nessa perspectiva, os três estados de maior vulnerabilidade para o jovem são: Alagoas $(0,489)$, Ceará $(0,487)$ e Pará $(0,471)$. Santa Catarina $(0,209)$, São Paulo $(0,209)$ e Rio Grande do Sul $(0,216)$ são os estados com menor vulnerabilidade. Chama atenção a posição do Distrito Federal $(0,225)$ no ranking, quarto estado com menor vulnerabilidade, mas com risco relativo de homicídio entre jovens negros e brancos no valor de 3,37 , ou seja, mesmo que a violência seja baixa ela incide seletivamente nos jovens negros. (UNESCO, BRASIL, 2017, p.94).

Por outro lado, observa-se que os índices apresentam dados socioeconômicos e demográficos produzidos por diferentes fontes (Instituto Brasileiro e Geográfico - IBGE e Sistema de Informações de Mortalidade do Ministério da Saúde) e resumem o efeito de múltiplas variáveis que interagem para compor as condições de vida da população jovem do país. Os anos base dos índices dizem respeito aos anos disponíveis nas fontes originais de pesquisa dos dados quando da realização dos estudos.

As informações constantes do estudo, sejam por unidade da federação ou por municípios com mais de 100 mil habitantes (em 2015), são elementos fundamentais para a elaboração de políticas públicas destinadas 
ao enfrentamento deste grave problema social. Desse modo, a violência reduz a expectativa de vida da população:

E representa um obstáculo considerável ao desenvolvimento do Estado Brasileiro. Há indícios de que, por meio de políticas públicas voltadas para esse segmento da população, desde que sejam adequados e localizados, avanços significativos poderão ser alcançados (BRASIL. UNESCO, 2017, SP. p. 92).

Nos índices visitados, acima descritos, foi recorrente a incidência de maior grau de mortalidade para a juventude negra no país, independente do gênero pesquisados. Por se considerar a educação como essencial para o desenvolvimento do ser humano no campo histórico, geográfico, cultural, social, responsável pela transformação positiva da sociedade, necessita ser vista e considerada como um direito fundamental do indivíduo e dever do Estado, que tem a responsabilidade de implementar políticas públicas capazes de garanti-las com qualidade. O único e exclusivo caminho que possibilitará as melhores condições socioeconômicas de uma nação é a educação que, uma vez valorizada, propiciará oportunidades de igualdade para todas as classes sociais.

\section{CONSIDERAÇÕES}

É preciso pensar em políticas educacionais como essência para o norteamento da cidadania e para a formação de uma base nacional igualitária e verdadeiramente ativa. Não basta a criação de "Reforma Educacional", simplesmente para atender convicções políticas, o que se espera é por um sistema que possa atender as reais necessidades da nação, atenuando as desigualdades sociais, desmascarando e fortalecendo o senso crítico dos indivíduos.

As políticas públicas surgiram com o intuito de viabilizar a construção do bem comum de todos os cidadãos que integram a sociedade. Cabe, pois, o Estado refletir sobre o compromisso que a ação governamental tem com as suas implementações, para que contribuam com a transformação educacional e a efetivação da cidadania, em virtude dos direitos previstos na Constituição Federal.

É percebível que as políticas educacionais, no Brasil, avançaram 
bastante nas últimas décadas, mas é percebível também, que os seus efeitos não atingiram grande parte das metas almejadas. Com isso, fica a sociedade credenciada a lutar por um ensino de qualidade, que possibilite a melhoria do nível de desenvolvimento do nosso país.

\section{REFERÊNCIAS}

ABNT - Associação Brasileira de Normas Técnicas. NBR 14724: Informação e documentação. Trabalhos Acadêmicos - Apresentação. Rio de Janeiro: ABNT, 2002.

ABRAMOVAY, $M$. et al. Juventude, violência e vulnerabilidade social na América Latina: desafios para políticas públicas. Brasília: UNESCO, 2002. Disponível em: <unesdoc.unesco.org/images/0012/001271/127138por.pdf>. Acesso em: 18 nov.2012.

ARRIAGADA, I. Famílias vulnerables o vulnerabilidad de las famílias? In: CEPAL. Seminario Vulnerabilidad. Santiago de Chile, 2001.

BRASIL Hidden in Plain Sight. Portal brasileiro do Fundo das Nações Unidas para a Infância - UNICEF, 2017.

BOURDIEU, P. O Poder simbólico. Rio de Janeiro: Bertrand Brasil, 2001.

BUSSO, G. Vulnerabilidad social: nociones e implicâncias de políticas para Latinoamerica a inícios Del siglo XXI. Seminário Internacional. "Las diferentes expresiones de la vulnerabilidad social em América Latina y el Caribe" - Santiago de Chile, 20 y 21 de junio de 2001.

BRUSEKE, F. J. Risco e Contingência. Os paradigmas da modernidade e sua contestação. Revista Brasileira de Ciências Sociais, 1 ed. Florianópolis: Editora Insular, 2006

CASTRO, M. G.; ABRAMOVAY, M. Cultura, identidades e cidadania: experiências com adolescentes em situação de risco. In: Comissão Nacional de População e Desenvolvimento. Jovens acontecendo na trilha das políticas públicas. Brasília: CNPD/Ipea, 1998.

CASTRO, M. G.; ABRAMOVAY, M. G. et al. Cultivando vida; desarmando violências: experiências em educação, cultura, lazer, esporte e cidadania com jovens em situação de pobreza. Brasília: Unesco, 2001.

DABAS, E. Redes sociales, familias y escuela. Buenos Aires: Paidós, 2005.

IHA. Índice de Homicídios na Adolescência. 2012.

LÉVY, A. Ciências clínicas e organizações sociais: Sentido e crise do 
sentido. Belo Horizonte: Autêntica/FUMEC, 2001.

MILANI, F. M. O adolescente, a família e a escola: uma visão integrada. I Congresso Nacional. A saúde do adolescente (p.389-402). Rio de Janeiro: Academia Nacional de Medicina, 1991.

MOSER, C. "The asset vulnerability framework: reassessing urban poverty reduction strategies". World Development 26(2), 1998.

KAZTMAN, R. et al. Vulnerabilidad, activos y exclusión social en Argentina y Uruguay. Santiago do Chile: OIT, 1999

CEPAL, 2000. (Borrador para discusión. 5 Taller regional, la medición de la pobreza, métodos e aplicaciones). www.eclac.cl/deype/noticias/proyectos. PIZARRO, Roberto, 2001.

PEREIRA, S. E. F. N. Redes sociais de adolescentes em contexto de vulnerabilidade social e sua relação com os riscos de envolvimento com - tráfico de drogas. Tese de Doutorado em Psicologia Clínica e Cultura. Instituto de Psicologia, Universidade de Brasília. Brasília, 2009.

VIGNOLI, J. R. Vulnerabilidad demográfica em América Latina: qué hay de nuevo? In: CEPAL. Seminario Vulnerabilidad. Santiago: Cepal, 2001.

WEBER, M. A Ética Protestante e o Espírito do Capitalismo. São Paulo: Ed. Cia das Letras, 1981.

UNESCO. Padrões de Competência em TIC para Professores. Tradução: Cláudia Bentes David. Versão 1.0. Paris: UNESCO, 2009. Disponível em: http://unesdoc.unesco.org/images/0015/001562/156209por.pdf. Acesso em: 20 maio 2017. 